\title{
Evaluation of high-resolution satellite precipitation products using rain gauge observations over the Tibetan Plateau
}

\author{
Y. C. Gao ${ }^{1}$ and M. F. Liu ${ }^{1,2,3}$ \\ ${ }^{1}$ Institute of Geographical Sciences and Natural Resources Research, Chinese Academy of Sciences, P.O. Box 9719, \\ Beijing, 100101, China \\ ${ }^{2}$ Graduate School of the Chinese Academy of Sciences, Beijing, 100039, China \\ ${ }^{3}$ Department of Civil and Environmental Engineering, Princeton University, Princeton, New Jersey, USA
}

Correspondence to: M. F. Liu (vanni05@gmail.com)

Received: 16 July 2012 - Published in Hydrol. Earth Syst. Sci. Discuss.: 15 August 2012

Revised: 9 January 2013 - Accepted: 18 January 2013 - Published: 28 February 2013

\begin{abstract}
High-resolution satellite precipitation products are very attractive for studying the hydrologic processes in mountainous areas where rain gauges are generally sparse. Four high-resolution satellite precipitation products are evaluated using gauge measurements over different climate zones of the Tibetan Plateau (TP) within a $6 \mathrm{yr}$ period from 2004 to 2009. The four satellite-based precipitation data sets are: Tropical Rainfall Measuring Mission (TRMM) Multisatellite Precipitation Analysis 3B42 version 6 (TMPA) and its Real Time version (TMPART), Climate Prediction Center Morphing Technique (CMOPRH) and Precipitation Estimation from Remotely Sensed Information using Artificial Neural Network (PERSIANN). TMPA and CMORPH, with higher correlation coefficients and lower root mean square errors (RMSEs), show overall better performance than PERSIANN and TMPART. TMPA has the lowest biases among the four precipitation data sets, which is likely due to the correction process against the monthly gauge observations from global precipitation climatology project (GPCP). TMPA also shows large improvement over TMPART, indicating the importance of gauge-based correction on accuracy of rainfall. The four products show better agreement with gauge measurements over humid regions than that over arid regions where correlation coefficients are less than 0.5 . Moreover, the four precipitation products generally tend to overestimate light rainfall $(0-10 \mathrm{~mm})$ and underestimate moderate and heavy rainfall $(>10 \mathrm{~mm})$. Moreover, this study extracts 24 topographic variables from a DEM (digital elevation model) and uses a linear regression model to explore the bias-topography relationship. Results show that biases of TMPA and CMORPH
\end{abstract}

present weak dependence on topography. However, biases of TMPART and PERSIANN present dependence on topography and variability of elevation and surface roughness plays important roles in explaining their biases.

\section{Introduction}

The Tibetan Plateau (TP) is one of the highest plateaus in the world with an average altitude of more than $4000 \mathrm{~m}$ a.s.l. (above sea level) and an area of about 2.4 million $\mathrm{km}^{2}$. The TP is the water source area of some important rivers (e.g. Yangzte, Yellow, Lancang-Mekong, Salween-Nujiang and Brahmaputra), which greatly affect hundreds of millions of people living in China. The TP has a significant thermal difference from its peripheral areas, known as heating source in the summer and cooling source in the winter, which has a far-reaching impact on the Asian monsoon systems and the formation of the East China climate (Yeh and Gao, 1979; Yanai et al., 1992). Wang et al. (2003) found that the evolution and eastward motion of convective cloud systems over the TP played important roles in the development and strengthening of rainstorms for the Yangtze River in 1998, which produced severe floods that killed thousands of people and destroyed about seven million houses. Shi et al. (2008) additionally found that the mesoscale feature in topography enhanced mesoscale disturbances over the TP, which propagated eastward and caused the increase of precipitation for the Yangtze River in 1998. Understanding the meteorological variations 
and hydrological processes of the TP cannot be overemphasized. Yang et al. (2011) suggested that observed precipitation showed insignificant increasing trends over the central TP and decreasing trends along the TP periphery. However, their results are based on rain gauges and may lose the representativeness due to the low gauge density over the TP. Thus, it is important to explore accurate documentation of the temporal and spatial distribution of precipitation.

The development of remote sensing technology has brought unprecedented opportunity to estimate precipitation by using radiometric observations. They can be classified into two main groups (Sapiano and Arkin, 2009). (1) Infrared (IR) imagery, which benefits from the high sampling frequency but yields crude estimates of precipitation because of the indirect relationship between cloud-top temperature and precipitation. (2) Microwave (MW), which tends to produce more accurate precipitation retrievals due to the direct connection with rainfall, but suffers from infrequent temporal sampling problem. Recently, several high-resolution precipitation products $\left(0.25^{\circ}\right.$ and 3 hourly) by merging MW and IR data have emerged, such as Precipitation Estimation from Remotely Sensed Information using Artificial Neural Networks (PERSIANN; Hsu et al., 1999; Sorooshian et al., 2000), Climate Prediction Center Morphing Method (CMORPH; Joyce et al. 2004), and TRMM Multisatellite Precipitation Analysis (TMPA; Huffman et al., 2007). They have been used in many different ways such as climate studies and hydrological analysis (e.g. Gottschalck et al., 2005; Shi et al., 2008; Pan et al., 2010).

Although high-resolution precipitation products provide a strong basis for studying the hydrologic processes in large mountainous areas, the accuracies need to be validated. There have been several studies focusing on the evaluation of the performance of high-resolution precipitation products over mountainous regions. Hong et al. (2007) compared PERSIANN-CCS (an improved version of PERSIANN; Hong et al., 2004) rainfall estimation with rain gauge observations in a complex terrain region of northwestern Mexico. They reported that PERSIANN-CCS tended to underestimate the occurrence of light precipitation at high elevation and to overestimate the occurrence of precipitation in low elevation, resulting in an overall positive bias in PERSIANN-CCS. In Ethiopia, Hirpa et al. (2010) evaluated three high-resolution precipitation products over complex terrain at annual timescale and found that PERSIANN could not show the elevation-dependent trend exhibited in TMPA 3B42RT (the real-time version without correction against gauge observations), CMORPH and gauge measurements. The superiority of MW-based TMPA 3B42 and CMORPH to IR-based PERSIANN over Ethiopia has also been validated by Dinku et al. (2008) at daily scales and Romilly and Gebremichael (2011) at monthly scales. Romilly and Gebremichael (2011) indicated that the impact of elevation on the performance of satellite estimates must be region specific. Sorooshian et al. (2011) also recommended that error properties of satellite-based precipitation should be studied in different climate regions and altitudes.

Yin et al. (2008) built a topography-based correction method for satellite-based precipitation estimates and found that TRMM 3B42 version 5 (an earlier version of TMPA) generated consistent overestimation over the TP at a monthly timescale. They also reported obvious improvements over $3 \mathrm{~B} 42$ version 5 when considering the performance of TRMM 3B43 version 6 that incorporated more MW data including the Special Sensor Microwave Imager (SSM/I) and Advanced Microwave Sounding Unit (AMSU). The corrected satellite monthly rainfall estimates showed significant improvements over original satellite estimates when a regression model was used based on gauge locations and topographic variables. However, their study was confined to monthly rainfall while hydrological process studies are, generally, at least based on a daily scale. Our study focuses on the evaluation of four widely used satellite-based precipitation products in specific climate zones over the TP at a daily timescale. We also try to explore the relationship between topography and satellite rainfall estimates at daily timescales because results by Yin et al. (2008) imply that topographic variables may be capable of interpreting errors of satellite rainfall data. The performance of the satellite precipitation estimates is expected to provide suggestions for the application of these precipitation products over the TP. This paper is organized as follows: Sect. 2 provides a description of data sets and method; Sect. 3 discusses the comparison between high-resolution satellite precipitation data sets and rain gauge observations and the topographic impact on biases of satellite estimates, and a summary is given in Sect. 4 .

\section{Data and method}

\subsection{Study area}

The TP is located in northwestern China, including Xizang (Tibet), Qinghai, Gansu, southern Xinjiang and the western Sichuan province. Our study mainly focuses on the area of $25-40^{\circ} \mathrm{N}$ and $75-105^{\circ} \mathrm{E}$ with mean elevation of about $4292 \mathrm{~m}$ (Fig. 1). Topography plays an important role in creating disparate microclimates ranging from deserts to forests. For example, the average elevation of Qaidam basin is largely lower than peripheral regions, which prevents water vapor from flowing into the basin to form rainfall and leads to its being an extremely arid area. Sun and Zheng (1999) divided the TP and its peripheral regions into zones according to climatic factors shown in Table 1 (Fig. 2). For example, the Qaidam basin is located in the zone of HIID1 characterized as a temperate and arid zone. Table 2 presents mean elevation, $6 \mathrm{yr}$ mean rainy season precipitation and the number of rain gauges within every zone. Arid zones generally receive rainfall less than $150 \mathrm{~mm}$ while humid zones receive more than $600 \mathrm{~mm}$ except zone IVA. TMPA, CMORPH 


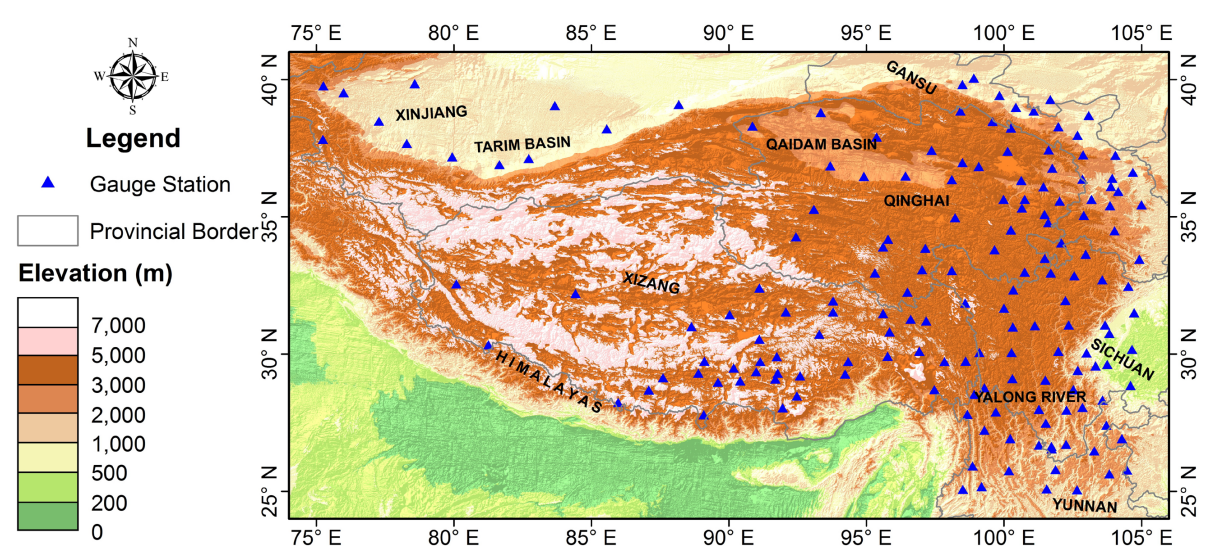

Fig. 1. The rain gauge network consisted of 166 stations used in our study, and the elevation pattern over the entire Tibetan Plateau and its peripheral regions.

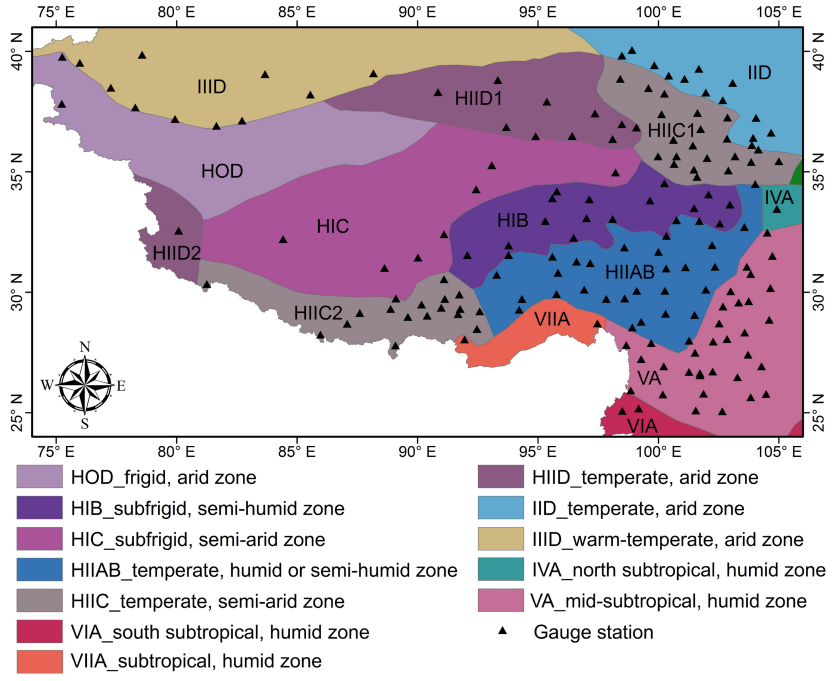

Fig. 2. The climate zones over the Tibetan Plateau and its peripheral areas and the 166 rain gauges (Sun and Zheng, 1999).

and PERSIANN are used to roughly assign the rainy season precipitation because they can provide continuous coverage. TMPART is excluded because it produces a less accurate rainfall field than TMPA. However, it is worth noting that they are all biased and will be evaluated later.

\subsection{Satellite precipitation data}

High-resolution precipitation products PERSIANN, TMPA 3B42 version 6 and Real Time version (TMPART) and CMORPH that map global precipitation at 3-hourly and $0.25^{\circ}$ resolution are examined in our study. A good and detailed description of them and their inputs are available in Sapiano and Arkin (2009). We, here, only briefly summarize the algorithms for retrieving rainfall. In the PERSIANN algorithm, an artificial neural network is used to train IRprecipitation relationship with TRMM Microwave Imager
Table 1. The indices that are used to divide the TP into climate zones. Note that ET denotes annual evapotranspiration $(\mathrm{mm})$, and $P$ denotes annual precipitation (Sun and Zheng, 1999).

\begin{tabular}{lllll}
\hline Indices & $\begin{array}{l}\text { Number } \\
\text { of days }\end{array}$ & Indices & Dryness & $\begin{array}{l}\text { Annual } \\
\text { precipitation } \\
(\mathrm{mm})\end{array}$ \\
\hline Subtropical & $>180$ & Humid & $<1.0$ & $>800$ \\
Warm-temperate & $141-180$ & Semi-humid & $1.0-1.5$ & $500-800$ \\
Temperate & $51-140$ & Semi-arid & $1.6-5.0$ & $200-499$ \\
Sub frigid & $1-50$ & Arid & $5.1-15$ & $50-199$ \\
Frigid & 0 & - & - & - \\
\hline
\end{tabular}

(TMI) and other MW data (Hsu et al., 1999; Sorooshian et al., 2000). The trained network is then applied to determine precipitation estimates based on IR measurements. TMPART establishes IR-precipitation relationship by matching the probability density function between MW precipitation retrievals and IR observations (Huffman et al., 2007). MW estimates are preferentially used when MW data are available, and IR estimates are used to fill the grids that are not covered by MW retrievals. The combined precipitation estimates are then calibrated and rescaled using the GPCP monthly gauge data measured over land (Huffman et al., 1997). The difference between TMPA and TMPART is that TMPART is the real time version without gauge correction. Based on IR measurements, CMORPH constructs motion vectors of cloud systems to interpolate the infrequent MW estimates with time to create consistent time series for precipitation (Joyce et al., 2004).

\subsection{Rain gauge data}

We collect a surface precipitation data set from the National Meteorological Information Center of the China Meteorological Administration (CMA). The data set consists of daily precipitation records during 2004-2009 at 166 rain gauges located in the central TP and its peripheral areas (Fig. 1). 
Table 2. Characteristics of the climate zones. Meanings of the zone names are referred to Fig. 2. The rainy season precipitation here refers to six months from May to October and is calculated as the median of TMPA, CMORPH and PERSIANN estimates.

\begin{tabular}{lccrlrrr}
\hline Zones & $\begin{array}{c}\text { Mean } \\
\text { elevation } \\
(\mathrm{m})\end{array}$ & $\begin{array}{c}\text { Rainy } \\
\text { season } \\
\text { precipitation } \\
(\mathrm{mm})\end{array}$ & $\begin{array}{c}\text { Number } \\
\text { of rain } \\
\text { gauges }\end{array}$ & Zones & $\begin{array}{c}\text { Mean } \\
\text { elevation } \\
(\mathrm{m})\end{array}$ & $\begin{array}{r}\text { Rainy } \\
\text { season } \\
\text { precipitation } \\
(\mathrm{mm})\end{array}$ & $\begin{array}{r}\text { Number } \\
\text { of rain } \\
\text { gauges }\end{array}$ \\
\hline HOD & 4363 & 119 & 3 & HIID2 & 4949 & 134 & 1 \\
HIB & 4499 & 505 & 15 & IID & 1507 & 155 & 13 \\
HIC & 4870 & 243 & 7 & IIID & 1224 & 96 & 9 \\
HIIAB & 4145 & 621 & 30 & IVA & 1849 & 474 & 1 \\
HIIC1 & 3239 & 363 & 22 & VA & 1699 & 684 & 33 \\
HIIC2 & 4920 & 332 & 18 & VIA & 1642 & 705 & 2 \\
HIID1 & 3347 & 123 & 10 & VIIA & 2552 & 616 & 2 \\
\hline
\end{tabular}

A strict quality control process has been applied by CMA to check and validate extreme values. Wind and snow can cause inaccuracies to rain gauge observations (Legates and Willmott, 1990). Therefore, our study only refers to summer and fall seasons from May to October. It is worth noting that the selected months cover rainy seasons and the accumulated precipitation in these months account for $86.8 \%$ of the annual precipitation from 2004 to 2009 . Note that the accumulated and annual precipitation is simply calculated as the spatial mean value of the 166 gauge measurements over TP.

It is not possible to reach perfect spatial matching between point measurements from gauges and spatially averaged estimates from satellite products (Hong et al., 2007; Sapiano and Arkin, 2009; Hirpa et al., 2010; Romilly and Gebremichael, 2011). Fundamental difficulties exist when comparing gauge measurements and satellite estimates: retrieval errors of satellite algorithms, sampling errors caused by different sampling schemes, systematic gauge errors related to instruments, etc. (Ciach and Krajewski, 1999; Bowman, 2005). However, this study is not aimed to precisely quantify the errors of satellite estimates in individual rain events, but to evaluate the overall performance of satellite products over a long period and its relationship to local climate and topography. Moreover, we cover a period of six years (2004-2009) to create large rainfall samples that are expected to relieve the interference of sampling errors. Xie et al. (2007) constructed a gridded daily precipitation data set based on gauge observations over East Asia. The gridded data set performed well over most regions of China except over the TP. The sparse gauge network of the TP did not allow accurate estimation of an analyzed precipitation field. In order to avoid large inaccuracies caused by up-scaling interpolation, we follow a downscaling method used by Sapiano and Arkin (2009) that builds the matched rainfall series for each gauge station by combining the surrounding four grids points from the satellite analyses using bilinear interpolation. A good description of bilinear interpolation can be found in Wikipedia (http://en.wikipedia.org/wiki/Bilinearinterpolation). By integrating the nearest four grids instead of the single grid that contains the rain gauge, we expect to relieve errors caused by wind and other spatial sampling problems (Bell and Kundu, 2003; Bowman, 2005). Moreover, Demirtas et al. (2005) compared two types of verification techniques for model precipitation forecasts: "grid-to-grid" and "grid-to-point" with bilinear interpolation and found that the two methods led to similar conclusions. The 3-hourly precipitation in the satellite data sets is accumulated to daily rainfall following the method used in Shen et al. (2010). It should be noted that satellite products with Universal Time Coordinated (UTC) have been transformed to Local Standard Time (LST) to be consistent with rain gauges.

\subsection{Statistical indices}

To quantitatively compare satellite products with rain gauge measurements, a set of statistics are used in our study: correlations, bias and root mean square errors (RMSE). To detect the satellite's ability of delineating rain/no rain events, we also adopt a set of contingency table statistics: probability of detection (POD) that measures the ratio of rain occurrences correctly detected to the total number of observed events, false alarm ratio (FAR) that measures the ratio of the number of falsely alarmed rain events to the total number of detected events, and equitable threat score (ETS) that is modified to account for hits due to random chance (Schaefer, 1990; Ebert et al., 2007). Note that all the statistics are calculated based on time series of gauge points created by the previously mentioned downscaling method. The equations of these statistics are shown below.

$$
\begin{aligned}
& \text { Correlation }=\frac{\sum_{i=1}^{n}\left(G_{i}-\bar{G}\right)\left(S_{i}-\bar{S}\right)}{\sqrt{\sum_{i=1}^{n}\left(G_{i}-\bar{G}\right)^{2}} \times \sqrt{\sum_{i=1}^{n}\left(S_{i}-\bar{S}\right)^{2}}} \\
& \operatorname{Bias}=\frac{1}{n} \sum_{i=1}^{n}\left(S_{i}-G_{i}\right)
\end{aligned}
$$


Table 3. Topographic variables and their descriptions.

\begin{tabular}{|c|c|}
\hline Variable & Description \\
\hline MEAN_slp & Mean slope angle inside $0.25^{\circ}$ buffers \\
\hline MEAN_hshd & $\begin{array}{l}\text { Mean lighting condition inside } 0.25^{\circ} \text { buffers, as represented by relative solar radiation with solar azimuth at } \\
180^{\circ} \text { (south) and alt of } 55^{\circ}\end{array}$ \\
\hline MIN_dem & Minimum elev inside $0.25^{\circ}$ buffers \\
\hline MAX_dem & Maximum elev inside $0.25^{\circ}$ buffers \\
\hline RANGE_dem & Range of elev values inside $0.25^{\circ}$ buffers \\
\hline MEAN_dem & Mean elev inside $0.25^{\circ}$ buffers \\
\hline STD_dem & Std dev of elev inside $0.25^{\circ}$ buffers \\
\hline SUM_dem & Sum of all elev values inside $0.25^{\circ}$ buffers \\
\hline MEDIAN_dem & Median elev inside $0.25^{\circ}$ buffers \\
\hline MIN_relief & Minimum relative relief inside $0.25^{\circ}$ buffers, based on a $0.5^{\circ}$ search radius \\
\hline MAX_relief & Maximum relative relief inside $0.25^{\circ}$ buffers, based on a $0.5^{\circ}$ search radius \\
\hline MEAN_relief & Mean relative relief inside $0.25^{\circ}$ buffers, based on a $0.5^{\circ}$ search radius \\
\hline STD_relief & Std dev of relative relief inside $0.25^{\circ}$ buffers \\
\hline Flat_asp & Proportion of flat terrain inside $0.25^{\circ}$ buffers, where slope aspect is coded as 0 \\
\hline North_asp & Proportion of area with north-facing slopes inside $0.25^{\circ}$ buffers \\
\hline Northeast_asp & Proportion of area with northeast-facing slopes inside $0.25^{\circ}$ buffers \\
\hline East_asp & Proportion of area with east-facing slopes inside $0.25^{\circ}$ buffers \\
\hline Southeast_asp & Proportion of area with southeast-facing slopes inside $0.25^{\circ}$ buffers \\
\hline South_asp & Proportion of area with south-facing slopes inside $0.25^{\circ}$ buffers \\
\hline Southwest_asp & Proportion of area with southwest-facing slopes inside $0.25^{\circ}$ buffers \\
\hline West_asp & Proportion of area with west-facing slopes inside $0.25^{\circ}$ buffers \\
\hline Northwest_asp & Proportion of area with northwest-facing slopes inside $0.25^{\circ}$ buffers \\
\hline
\end{tabular}

$$
\begin{aligned}
& \text { RMSE }=\sqrt{\frac{1}{n} \sum_{i=1}^{n}\left(S_{i}-G_{i}\right)^{2}} \\
& \mathrm{POD}=\frac{H}{H+M} \\
& \mathrm{FAR}=\frac{F}{H+F} \\
& \mathrm{ETS}=\frac{H-H_{\mathrm{e}}}{H+M+F-H_{\mathrm{e}}},
\end{aligned}
$$

where, $G_{i}$ means gauge observations and $\bar{G}$ is the average of gauge observations. $S_{i}$ and $\bar{S}$ are satellite estimates and their average, respectively. $H$ : observed rain correctly detected; $M$ : observed rain not detected; $F$ : rain detected but not observed; $H_{\mathrm{e}}=(H+M)(H+F) / N$ and $N$ is the total number of estimates. Detailed information about contingency table statistics can be referred to Ebert et al. (2007).

\subsection{Topographic analysis}

An assembly of topographic variables including elevation, slope, aspect and local relief is used in our study. To match the topographic fields with bilinearly interpolated satellite rainfall fields, a buffer of $0.25^{\circ}$ is generated for each gauge station. Elevation, slope and aspect are then easily calculated from a digital elevation model (DEM) with a horizontal grid spacing of 30 arc seconds within the buffer. To obtain relief data, the DEM is first smoothed by a $101 \times 101$ moving window and the resultant surface represents the large-scale topographic features (Yin et al. 2008). The smoothed surface is then subtracted from the original DEM to generate local relieves that represent mountain peaks and ridgelines. All 24 topographic variables used in this study are described in Table 3. Because some variables listed in Table 3 are related to each other, principle component analysis (PCA) is used to reduce the redundancy in the topographic data set based on values of terrain variables at all 166 gauge stations. The results of PCA are rotated principle components (RPCs) that are orthogonal to each other. Each RPC contains original variables with similar effects on dependent variables. A linear regression model is then employed to interpret satellite rainfall biases based on RPCs. 
(a) TMPA

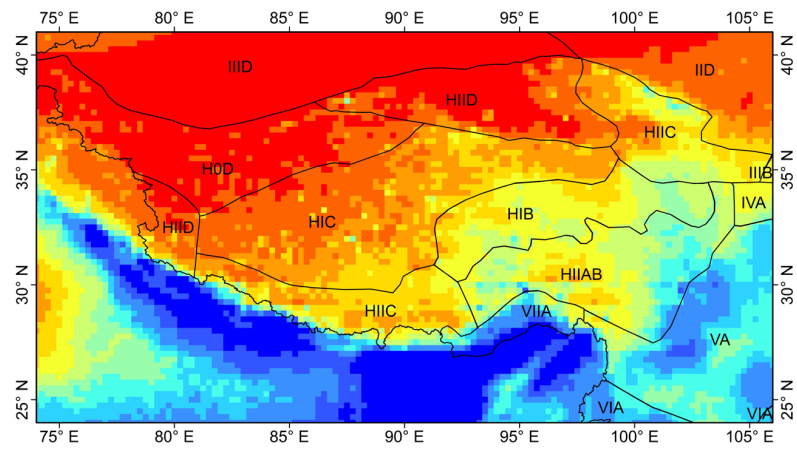

(c) PERSIANN

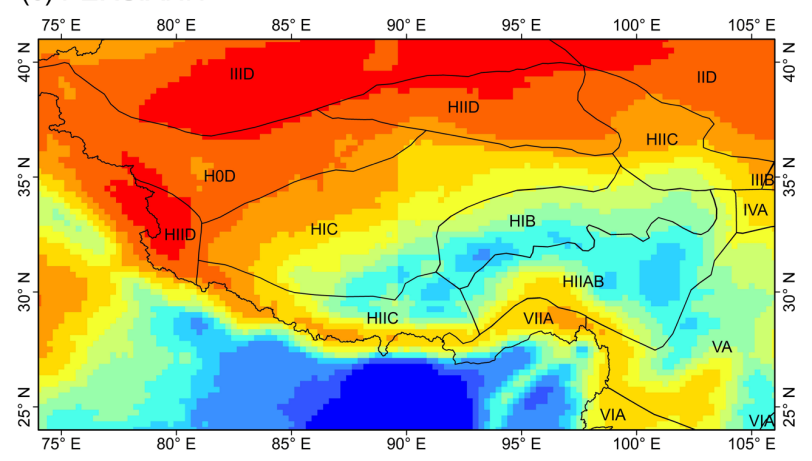

(b) $\mathrm{CMORPH}$

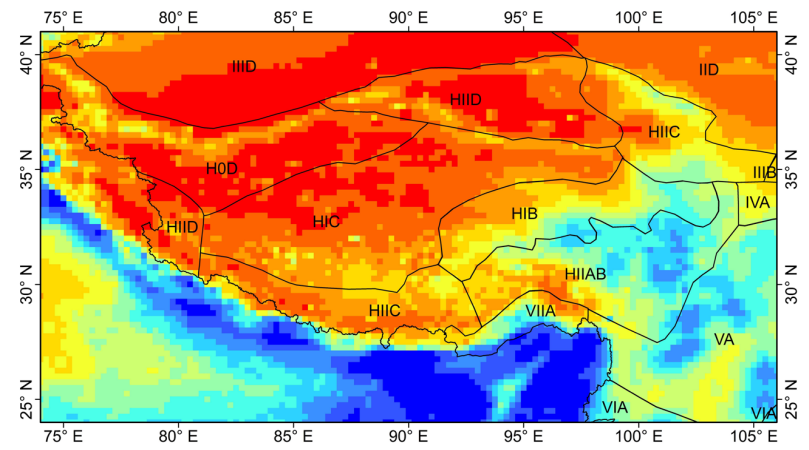

$\mathrm{mm}$

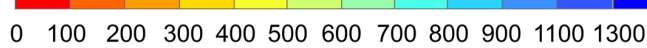

Fig. 3. The 6 yr mean rainy season precipitation during 2004-2009 for (a) TMPA, (b) CMORPH and (c) PERSIANN.

\section{Results and discussion}

\subsection{Spatial precipitation patterns of satellite data sets}

Figure 3 shows the spatial distribution of the 6yr mean rainy season precipitation of TMPA, CMORPH and PERSIANN over the TP and its peripheral areas. All three satellite data sets present an increasing trend of precipitation from northwest to southeast over the TP. They clearly reveal a small precipitation amount in the Tarim basin $\left(37-40^{\circ} \mathrm{N}\right.$, $80-90^{\circ} \mathrm{E}$, mainly located in zone IIID including Taklimakan desert) and Qaidam basin (35-39 $\mathrm{N}, 90-99^{\circ} \mathrm{E}$, located in zone HIID1) with cumulative rainfall less than $200 \mathrm{~mm}$, and abundant precipitation of about $1300 \mathrm{~mm}$ in the southern Himalayas where the Indian monsoon prevails. In addition, the strong contrast of precipitation pattern between northern and southern Himalayas identifies the orographic effect on precipitation (Barros et al., 2004). PERSIANN generates a large mass of precipitation over the central and southern TP (mainly located in HIB and HIIAB), while TMPA and CMORPH do not (Xie et al., 2007). This feature has been proved to be an overestimation when compared to gauge measurements.

\subsection{Evaluation according to climate zones}

We first examine how well satellite estimates detect rain events. A higher POD and ETS and a lower FAR are desirable. A threshold of $1.0 \mathrm{~mm} \mathrm{day}^{-1}$ adopted by Dai (2006) for studying global daily precipitation is used here to discriminate whether rain occurs. TMPA and CMORPH show similar statistics: CMORPH has slightly larger POD with mean value around 0.70, and TMPA has slightly smaller FAR with mean value around 0.35 (Fig. 4a and b). However, plus symbols below whiskers in Fig. 4a show that TMPA and CMORPH do not detect rain events well in several sites. Similarly, plus symbols above whiskers in Fig. 4b show that TMPA and CMORPH tend to give false alarms in some sites. TMPART shows the largest POD and FAR, indicating that it tends to produce rainfall over both rain and non-rain areas. Of the four data sets, PERSIANN has the smallest POD and ETS and the similar FAR as TMPART.

Spatial patterns of correlations and biases of the four products are illustrated in Figs. 5-6. Overall, of the three satellite products without gauge correction, $\mathrm{CMORPH}$, with larger correlation and smaller bias pattern, shows more correspondence with gauge measurements than TMPART and PERSIANN, which may be due to the fact that TMPART and PERSIANN use precipitation-IR relationships to estimate rainfall, while CMORPH only employs IR observations to predict advection vectors that are used to interpolate the infrequent MW retrievals but not employ them to directly estimate rainfall amount. The correlation between IR brightness temperature and rainfall is weak if little water is available in air profiles. PERSIANN has difficulties 

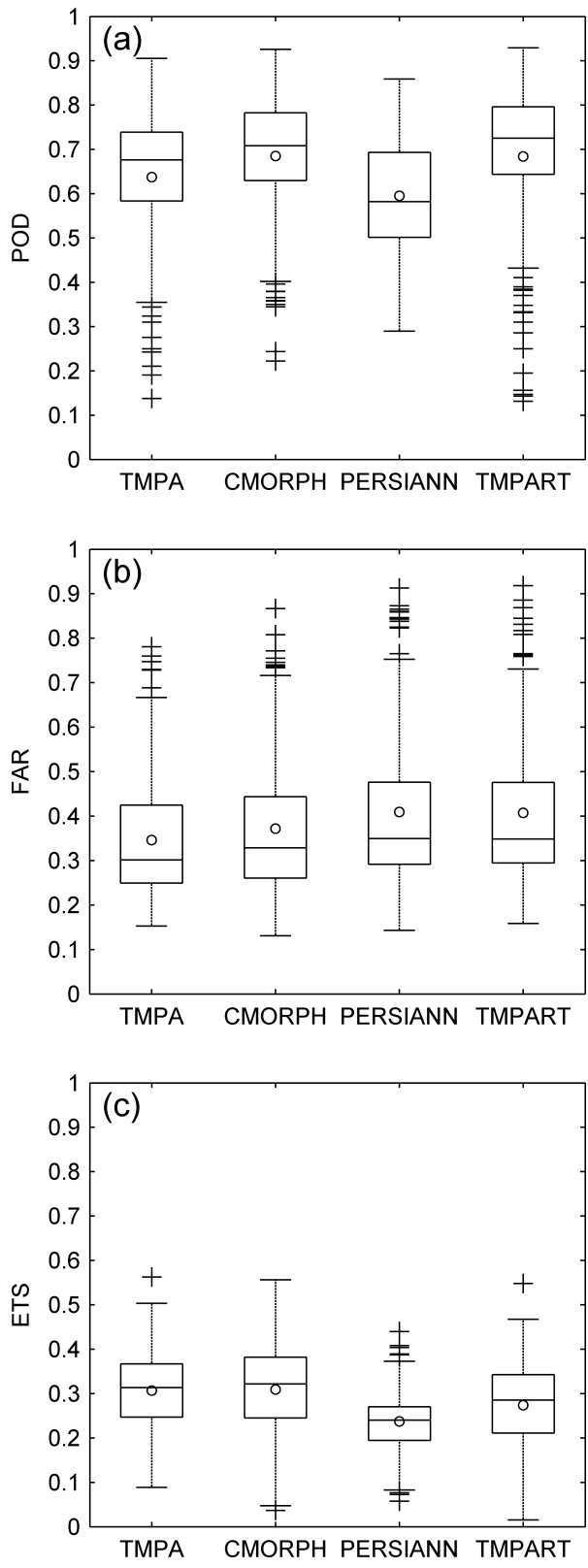

Fig. 4. Box plots of contingency table statistics for (a) POD, (b) FAR and (c) ETS. The circle represents the mean value. Each box ranges from the lower quartile (25th) to upper quartile (75th). The median is presented by the middle line in the box. The whiskers extend out to largest and smallest values within 1.5 times the interquartile range (difference between the 75 th and 25 th percentiles). The plus represents the points beyond the whiskers.

in addressing this condition since it is mainly based on IR brightness temperature in its neural network without incorporating water availability in profiles. TMPART has to use IR observations to estimate rainfall when MW retrievals are not available and it uses a different method from PERSIANN to establish precipitation-IR relationship. TMPART produces larger positive biases than other products over most gauges, indicating that it generates positive systematic errors over the TP (Fig. 6d). TMPA is unique of the other three satellite data sets, in that a correction process is used against the monthly gauge data of GPCP to reduce the inherent bias in satellite-based precipitation estimates. Correlations and biases of TMPA both show large improvement over TMPART, indicating the importance of integrating gauge observations into satellite estimates. The correlations of TMPA are comparable to those of CMORPH. Serial correlations of TMPA and CMORPH exceed 0.6 for most gauges of the Yalong River over the southeastern TP (Fig. 5a and b). Also, as shown in Fig. 6a, TMPA exhibits lower serial biases compared to other satellite estimates, which is consistent with studies over other regions, e.g. Korea (Sohn et al., 2010), and Pacific Ocean (Sapiano and Arkin, 2009).

A specific comparison for every climate zone is applied to further understand the applicability of the four satellite products over different climate zones of the TP. To assure the reliability of comparisons, only zones with at least 10 rain stations are selected. Statistics of every climate zone are averaged from gauges within the zones and shown in Table 4. Larger POD and ETS and lower FAR are observed over humid zones than over arid zones, and correlations present the similar situation. RMSE gradually increases from arid zones to humid zones, which may be due to higher amplitude of precipitation over more humid zones. The advantage of incorporating gauge observations over both humid and arid zones is clearly revealed from the comparison of correlation, bias and RMSE between TMPART and TMPA. Of the four data sets, TMPA exhibits the lowest biases over most zones and TMPART presents the largest biases, which is consistent with the bias pattern in Fig. 6. PERSIANN, generally with smaller POD, ETS and correlations and larger FAR, bias and RMSE, does not present the same good statistics as CMORPH and TMPA.

\subsection{Evaluation according to rainfall categories}

Rainfall categories may have an impact on the performance of satellite rainfall estimates. To explore different aspects of satellite products under different rainfall categories, rainfall is divided into four categories: 0-10, 10-25, 25-50, and $>50 \mathrm{~mm}$. The mean bias for each category is calculated for TMPART, TMPA, CMORPH and PERSIANN and the result is presented in Fig. 7. Overall, the four precipitation products generally tend to overestimate light rainfall $(0-10 \mathrm{~mm})$ and underestimate moderate and heavy rainfall ( $>10 \mathrm{~mm}$ ), except that TMPART produces obvious overestimation over zone HIIC2 for all categories. The underestimation for moderate and heavy rainfall increases as rainfall category increases. TMPART generally produces higher biases than other products, which as it is shown in Fig. 6d TMPART overestimates rainfall at most gauges over the TP. TMPA generally has higher performance than PERSIANN and CMORPH over most zones, showing the effect 

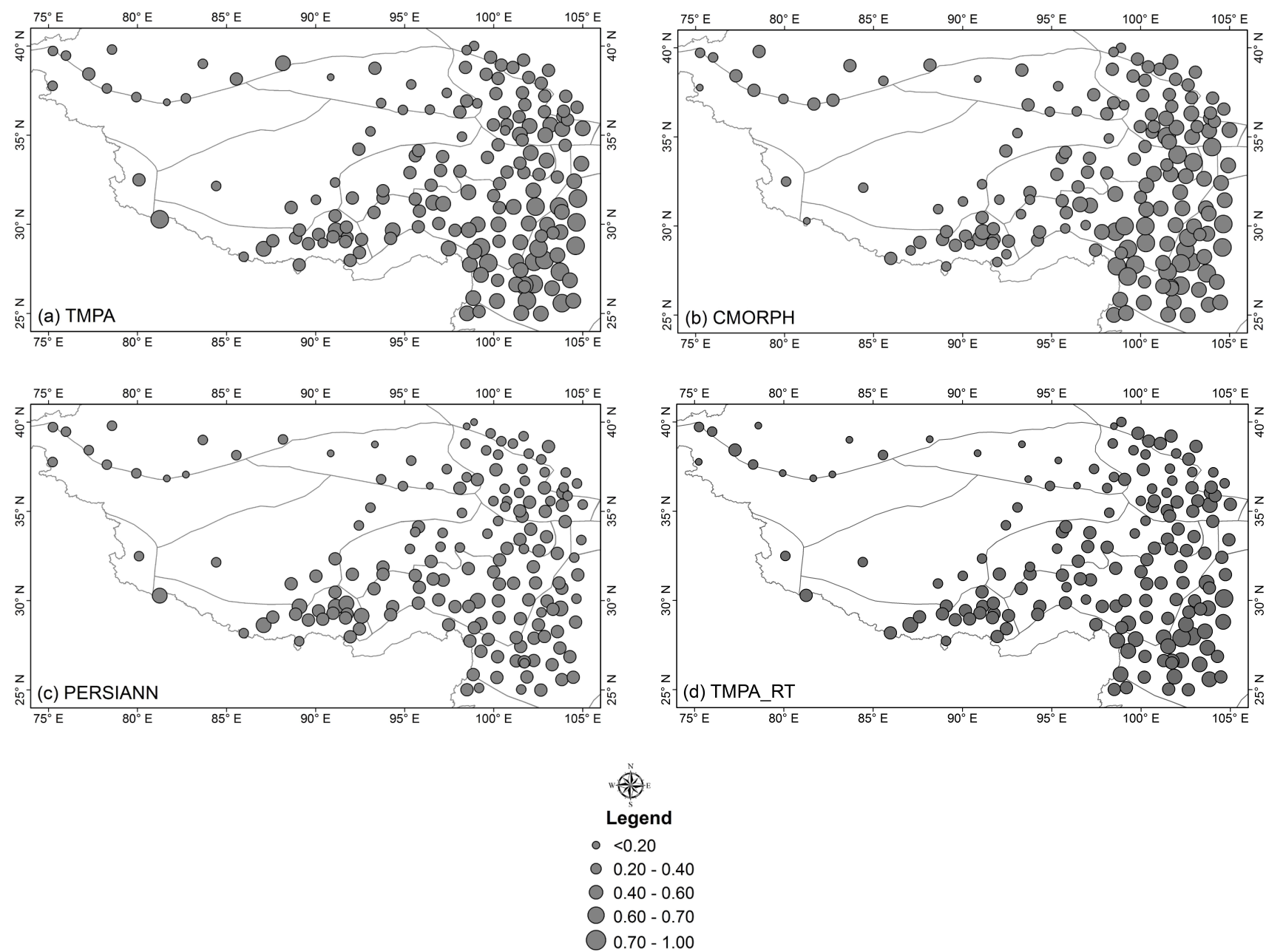

Fig. 5. The spatial pattern of correlations between gauge-based daily precipitation and that derived from satellite products from May to October during 2004-2009. Note that every circle depicts a gauge station.

of incorporating gauge stations for correction. In general, PERSIANN tends to produce a higher positive bias for light rainfall and lower negative bias for moderate and heavy rainfall than TMPA and CMORPH. It is also interesting to note that the negative biases in semi-arid and arid zones is lower than those in semi-humid and humid zones, showing that the four satellite-based precipitation products are not good at estimating moderate and heavy rainfall in arid zones compared to humid zones.

\subsection{Evaluation as a function of topography}

In PCA, the first seven rotated principle components (RPCs) are determined because they explain more than $90 \%$ of the variance of the original topographic data set, which means that left RPCs are not significant to determine the bias. Table 5 lists original variables represented by the seven RPCs. Note that only original variables with absolute loading values larger than 0.6 are listed because they are main topographic factors related to satellite rainfall biases. A linear regression model is employed to interpret rainfall biases based on RPCs. Note that all variables are normalized before they are used in the model. The regression model is first run using all the seven RPCs. Then only PRCs with significant level lower than 0.01 are maintained for analysis. Results of regression models are shown in Table 6. TMPA shows the lowest correlation with $R^{2}$ less than 0.1 . This result may be ascribed that bias-calibrated procedures using gauge data employed in TMPA made it less possible to explore biases of the satellite itself. Biases of CMORPH also present low correlation with topography. Contrary to TMPA, topography can best explain biases of TMPART. The highest coefficient of RPC2 in the regression model implies that elevation plays important roles in explaining biases because RPC2 mainly represents variability of elevation and surface roughness. PERSIANN also shows similar results. The difference is that PERSIANN requires more topographic variables to interpret biases, especially aspect. This indicates that a simple bias-elevation relationship may not be enough to 

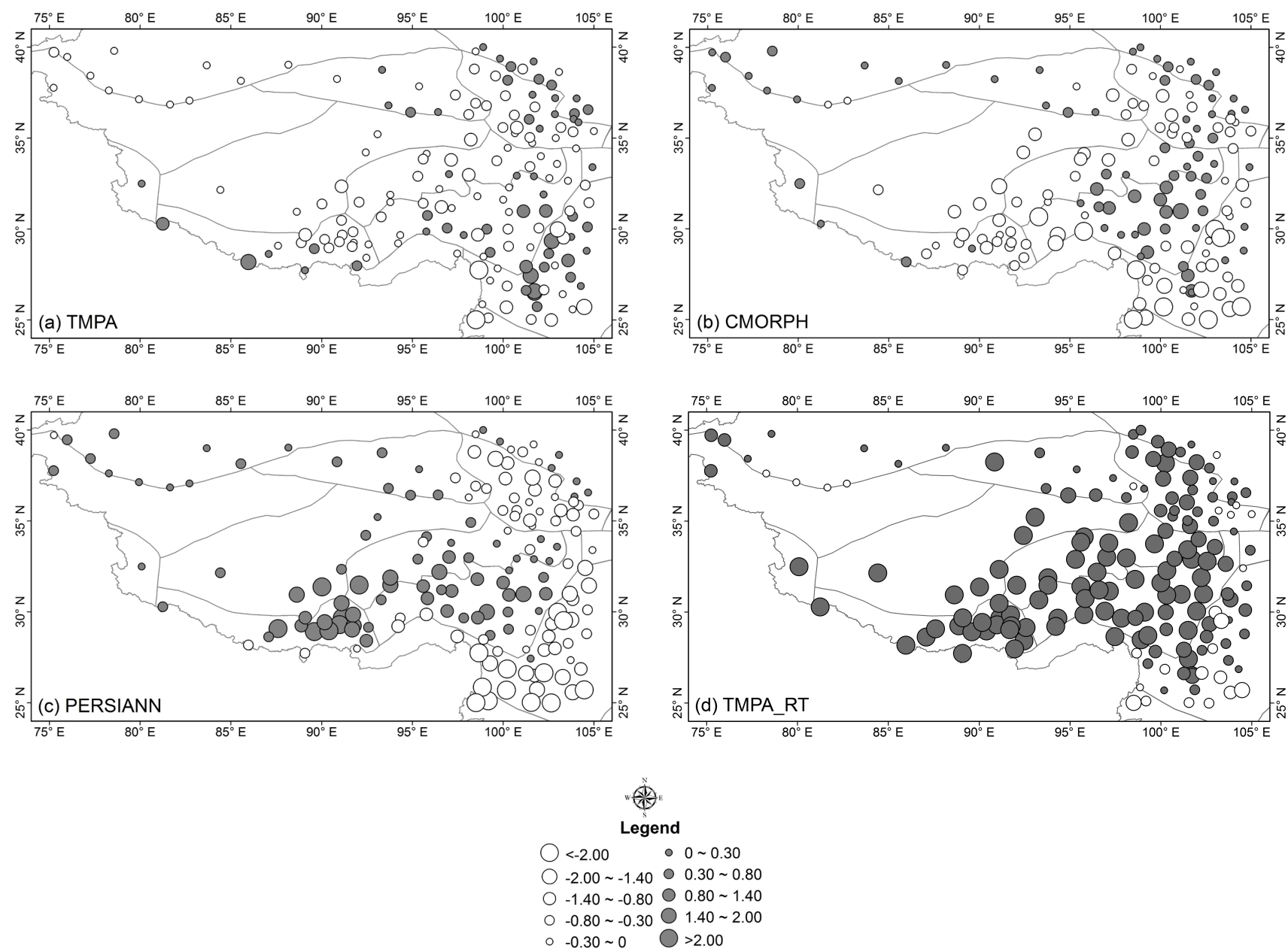

Fig. 6. The spatial pattern of biases $=S-G\left(\mathrm{~mm} \mathrm{day}^{-1}\right)$ between gauge-based daily precipitation and that derived from satellite products from May to October during 2004-2009.

interpret biases of satellite rainfall estimates. It is also interesting to note that PERSIANN and TMPART both employ IR-rainfall relationships to estimate rainfall while CMORPH does not. The bias-topography effect may be attributed to the impact of topography on IR observations.

\section{Summary and conclusions}

Several studies (e.g. Xie et al., 2007; Shen et al., 2010) were involved in the examination of the performance of satellite precipitation products over China. However, as far as we know, the examination over the TP has not been specifically studied. We here provide a detailed evaluation of satellite precipitation at a daily scale over the TP with specific focus on the different climate zones. We also extract 24 topographic variables from DEM, and use a linear regression model to explore the bias-topography relationship. Four satellite precipitation products are compared against rain gauge measurements collected from CMA. A long validation period from May to October during 2004-2009 is chosen to avoid spurious results caused by spatial sampling or random errors. The major findings are summarized as follows.

1. With higher correlation and lower RMSE, TMPA and CMORPH show better performance than PERSIANN and TMPART over the TP. TMPART produces obvious positive biases over most gauges.

2. Due to the correction process against monthly gauge measurements, TMPA shows large improvements over TMPART and displays the lowest biases among the four satellite rainfall products.

3. The four products show better agreement with rain gauge measurements in humid regions than that in arid regions.

4. The four precipitation products generally tend to overestimate light rainfall $(0-10 \mathrm{~mm})$ and underestimate moderate and heavy rainfall $(>10 \mathrm{~mm})$. 

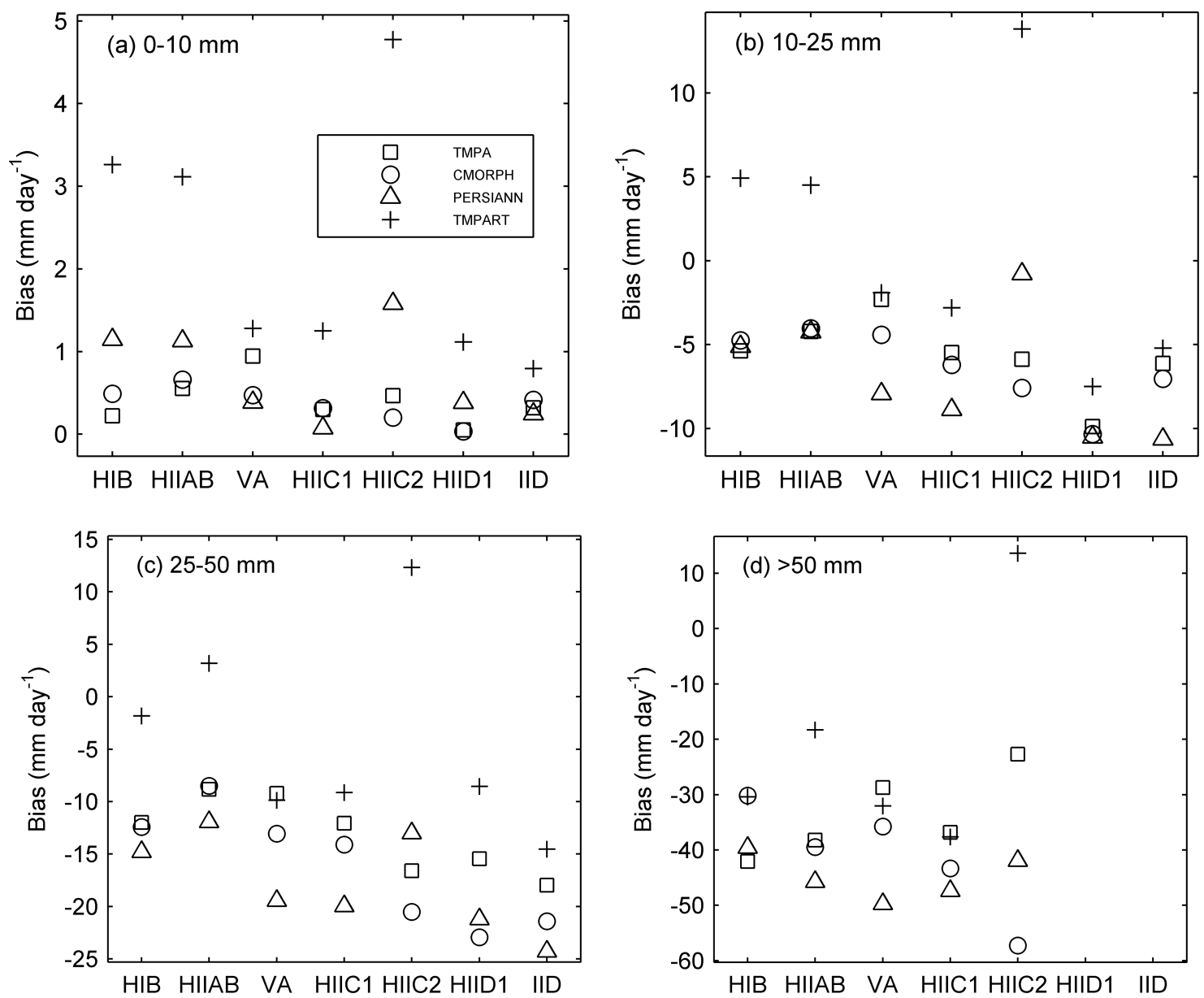

Fig. 7. Bias of satellite-based precipitation products for different rainfall categories.

5. Biases of TMPA and CMORPH show weak dependence on topography. However, biases of TMPART and PERSIANN present dependence on topography. Also, variability of elevation and surface roughness play important roles in explaining their biases.

Given the sparse distribution of meteorological stations over the TP, especially in regions at high elevations, satellitebased precipitation data sets provide an important way to map temporal and spatial patterns of precipitation. One goal of our study is to evaluate these satellite precipitation products with rain gauge observations before they are integrated into a global circulation model to simulate global hydrometeorological processes, or into a land surface model to understand regional hydrological processes. TMPA that is gaugecalibrated and CMORPH that depends heavily on MW data produce better precipitation estimates than PERSIANN that relies primarily on IR data and TMPART that has to adopt the IR-rainfall relationship when MW data is not available. This result is consistent with other similar studies over different areas of the world, showing the advantages of gauge-calibration and incorporating MW data. There are two suggestions for the future work. First, the satellite-based data sets generate reasonable estimates of precipitation. However, a correction process based on topography, gauge observations or humidity at daily or finer timescales is valuable to relieve systematic biases to provide a more accurate precipitation input for global or regional modelling. Second, although our study covers most regions across the TP, nearly no gauges exist over the northwestern TP where elevation is nearly higher than $4500 \mathrm{~m}$, so a denser precipitation observing network is needed in these regions for better comparison. 
Table 4. Evaluation statistics (calculated at a daily timescale) of rain gauge measurements versus satellite estimates over different zones.

\begin{tabular}{|c|c|c|c|c|c|c|c|c|}
\hline Indices & $\begin{array}{l}\text { Zone } \\
\text { name }\end{array}$ & $\begin{array}{l}\text { Satellite } \\
\text { data sets }\end{array}$ & POD & FAR & ETS & Correlation & Bias & RMSE \\
\hline \multirow[t]{4}{*}{ semi-humid } & \multirow[t]{4}{*}{ HIB } & TMPA & 0.67 & 0.25 & 0.30 & 0.50 & -0.32 & 5.19 \\
\hline & & CMORPH & 0.75 & 0.27 & 0.31 & 0.57 & -0.07 & 4.56 \\
\hline & & PERSIANN & 0.69 & 0.31 & 0.24 & 0.41 & 0.49 & 6.16 \\
\hline & & TMPART & 0.73 & 0.30 & 0.27 & 0.43 & 3.38 & 12.02 \\
\hline \multirow{4}{*}{$\begin{array}{l}\text { humid or } \\
\text { semi-humid }\end{array}$} & \multirow[t]{4}{*}{ HIIAB } & TMPA & 0.76 & 0.28 & 0.34 & 0.59 & 0.00 & 5.28 \\
\hline & & CMORPH & 0.78 & 0.31 & 0.33 & 0.62 & 0.14 & 4.98 \\
\hline & & PERSIANN & 0.69 & 0.30 & 0.29 & 0.48 & 0.45 & 6.56 \\
\hline & & TMPART & 0.80 & 0.33 & 0.30 & 0.50 & 3.22 & 11.51 \\
\hline \multirow[t]{4}{*}{ humid } & \multirow[t]{4}{*}{ VA } & TMPA & 0.74 & 0.27 & 0.37 & 0.67 & -0.03 & 8.93 \\
\hline & & CMORPH & 0.73 & 0.24 & 0.39 & 0.67 & -0.89 & 8.60 \\
\hline & & PERSIANN & 0.54 & 0.29 & 0.24 & 0.46 & -1.76 & 10.36 \\
\hline & & TMPART & 0.75 & 0.29 & 0.34 & 0.60 & 0.14 & 10.12 \\
\hline \multirow[t]{4}{*}{ semi-arid } & \multirow[t]{4}{*}{ HIIC1 } & TMPA & 0.63 & 0.34 & 0.29 & 0.55 & -0.22 & 4.93 \\
\hline & & CMORPH & 0.71 & 0.36 & 0.31 & 0.59 & -0.29 & 4.40 \\
\hline & & PERSIANN & 0.51 & 0.39 & 0.21 & 0.36 & -0.74 & 5.67 \\
\hline & & TMPART & 0.65 & 0.37 & 0.27 & 0.44 & 0.84 & 7.47 \\
\hline \multirow[t]{4}{*}{ semi-arid } & \multirow[t]{4}{*}{ HIIC2 } & TMPA & 0.69 & 0.35 & 0.34 & 0.54 & -0.05 & 4.67 \\
\hline & & CMORPH & 0.66 & 0.39 & 0.29 & 0.48 & -0.43 & 4.40 \\
\hline & & PERSIANN & 0.75 & 0.39 & 0.33 & 0.53 & 1.33 & 6.10 \\
\hline & & TMPART & 0.82 & 0.43 & 0.30 & 0.49 & 5.38 & 14.95 \\
\hline \multirow[t]{4}{*}{ arid } & \multirow[t]{4}{*}{ HIID1 } & TMPA & 0.37 & 0.58 & 0.18 & 0.32 & -0.15 & 2.63 \\
\hline & & CMORPH & 0.46 & 0.63 & 0.18 & 0.40 & -0.19 & 2.12 \\
\hline & & PERSIANN & 0.49 & 0.71 & 0.14 & 0.27 & 0.14 & 2.74 \\
\hline & & TMPART & 0.43 & 0.69 & 0.13 & 0.22 & 0.93 & 5.42 \\
\hline \multirow[t]{4}{*}{ arid } & \multirow[t]{4}{*}{ IID } & TMPA & 0.59 & 0.48 & 0.30 & 0.50 & 0.15 & 3.16 \\
\hline & & CMORPH & 0.70 & 0.50 & 0.33 & 0.51 & 0.19 & 2.92 \\
\hline & & PERSIANN & 0.48 & 0.59 & 0.20 & 0.29 & -0.06 & 3.43 \\
\hline & & TMPART & 0.55 & 0.55 & 0.24 & 0.40 & 0.61 & 4.71 \\
\hline
\end{tabular}

Table 5. Topographic variables represented by each RPC. Note that only variables with the most negative or the most positive loading values (i.e. absolute value $>0.6$ ) are listed. The values are in the bracket.

\begin{tabular}{|c|c|c|c|c|c|c|c|}
\hline & RPC1 & RPC2 & RPC3 & RPC4 & RPC5 & RPC6 & RPC7 \\
\hline \multirow[t]{7}{*}{ Variables } & $\begin{array}{l}\text { MEAN_slp } \\
(0.924)\end{array}$ & $\begin{array}{l}\text { MIN_dem } \\
(0.988)\end{array}$ & $\begin{array}{l}\text { Northeast_asp } \\
(-0.772)\end{array}$ & $\begin{array}{l}\text { North_asp } \\
(-0.714)\end{array}$ & $\begin{array}{l}\text { West_asp } \\
(0.814)\end{array}$ & $\begin{array}{l}\text { Flat_asp } \\
(0.714)\end{array}$ & $\begin{array}{l}\text { MEAN_relief } \\
(0.959)\end{array}$ \\
\hline & $\begin{array}{l}\text { MEAN_hshd } \\
(-0.700)\end{array}$ & $\begin{array}{l}\text { MAX_dem } \\
(0.876)\end{array}$ & $\begin{array}{l}\text { South_asp } \\
(0.858)\end{array}$ & $\begin{array}{l}\text { East_asp } \\
(0.835)\end{array}$ & $\begin{array}{l}\text { Northwest_asp } \\
(0.744)\end{array}$ & $\begin{array}{l}\text { Southwest_asp } \\
(0.630)\end{array}$ & \\
\hline & $\begin{array}{l}\text { RANGE_dem } \\
(0.964)\end{array}$ & $\begin{array}{l}\text { MEAN_dem } \\
(0.976)\end{array}$ & & $\begin{array}{l}\text { Southeast_asp } \\
(0.726)\end{array}$ & & & \\
\hline & $\begin{array}{l}\text { STD_dem } \\
(0.957)\end{array}$ & $\begin{array}{l}\text { SUM_dem } \\
(0.981)\end{array}$ & & & & & \\
\hline & $\begin{array}{l}\text { MIN_relief } \\
(-0.837)\end{array}$ & $\begin{array}{l}\text { MEDIAN_dem } \\
(0.976)\end{array}$ & & & & & \\
\hline & $\begin{array}{l}\text { MAX_relief } \\
(0.852)\end{array}$ & & & & & & \\
\hline & $\begin{array}{l}\text { STD_relief } \\
(0.959)\end{array}$ & & & & & & \\
\hline
\end{tabular}


Table 6. Regression model results of each satellite rainfall data set. Note that the model was developed based on data from all 166 stations. All variables in the model are independent and statistically significant at level 0.05 .

\begin{tabular}{lll}
\hline $\begin{array}{l}\text { Satellite } \\
\text { rainfall } \\
\text { data }\end{array}$ & $R^{2}$ & Regression model \\
\hline PERSIANN & 0.50 & Bias $=-0.174-0.146$ RPC $1+0.756$ RPC $2-0.169$ RPC $3-0.235$ RPC $4-0.196$ RPC6 + 0.366 RPC7 \\
CMORPH & 0.12 & Bias $=-0.313-0.133$ RPC $3+0.233$ RPC7 \\
TMPA RT & 0.60 & Bias $=1.940+0.593$ RPC1 +1.445 RPC2 +0.302 RPC7 \\
TMPA & 0.08 & Bias $=-0.112+0.111$ RPC1 -0.095 RPC2 \\
\hline
\end{tabular}

Acknowledgements. This research work is jointly supported by the National Natural Science Foundation of China (Grant no. 40871198) and the European Commission (Call FP7-ENV2007-1 Grant no. 212921) as part of the CEOP-AEGIS project (http://www.ceop-aegis.org/) coordinated by the Université de Strasbourg. We gratefully thank the National Meteorological Information Center of the China Meteorological Administration for providing rain gauge data.

Edited by: A. Langousis

\section{References}

Barros, A. P., Kim, G., Williams, E., and Nesbitt, S. W.: Probing orographic controls in the Himalayas during the monsoon using satellite imagery, Nat. Hazards Earth Syst. Sci., 4, 29-51, doi:10.5194/nhess-4-29-2004, 2004.

Bell, T. L. and Kundu, P. K.: Comparing satellite rainfall estimates with rain gauge data: Optimal strategies suggested by a spectral model, J. Geophys. Res.-Atmos., 108, 4121, doi:10.1029/2002jd002641, 2003.

Bowman, K. P.: Comparison of TRMM precipitation retrievals with rain gauge data from ocean buoys, J. Climate, 18, 178-190, 2005.

Ciach, G. J. and Krajewski, W. F.: On the estimation of radar rainfall error variance, Adv. Water Resour., 22, 585-595, doi:10.1016/s0309-1708(98)00043-8, 1999.

Dai, A.: Precipitation characteristics in eighteen coupled climate models, J. Climate, 19, 4605-4630, doi:10.1175/jcli3884.1, 2006.

Demirtas, M., Nance, L., Bernardet, L., Lin, Y., Chuang, H. Y., Loughe, A., Mahoney, J., Gall, R., and Koch, S.: The developmental testbed center verification system, http://www.mmm.ucar.edu/wrf/users/workshops/ WS2005/abstracts/Session3/23-DEMIRTAS.pdf (last access: 11 July 2012), June 2005

Dinku, T., Chidzambwa, S., Ceccato, P., Connor, S. J., and Ropelewski, C. F.: Validation of high-resolution satellite rainfall products over complex terrain, Int. J. Remote Sens., 29, 40974110, doi:10.1080/01431160701772526, 2008.

Ebert, E. E., Janowiak, J. E., and Kidd, C.: Comparison of near-real-time precipitation estimates from satellite observations and numerical models, B. Am. Meteorol. Soc., 88, 47-64, doi:10.1175/bams-88-1-47, 2007.
Gottschalck, J., Meng, J., Rodell, M., and Houser, P.: Analysis of multiple precipitation products and preliminary assessment of their impact on global land data assimilation system land surface states, J. Hydrometeorol., 6, 573-598, 2005.

Hirpa, F. A., Gebremichael, M., and Hopson, T.: Evaluation of High-Resolution Satellite Precipitation Products over Very Complex Terrain in Ethiopia, J. Appl. Meteorol. Clim., 49, 1044 1051, doi:10.1175/2009jamc2298.1, 2010.

Hong, Y., Hsu, K. L., Sorooshian, S., and Gao, X. G.: Precipitation Estimation from Remotely Sensed Imagery using an Artificial Neural Network Cloud Classification System, J. Appl. Meteorol., 43, 1834-1852, 2004.

Hong, Y., Gochis, D., Cheng, J.-T., Hsu, K.-L., and Sorooshian, S.: Evaluation of PERSIANN-CCS Rainfall Measurement Using the NAME Event Rain Gauge Network, J. Hydrometeorol., 8, 469482, doi:10.1175/jhm574.1, 2007.

Hsu, K. L., Gupta, H. V., Gao, X. G., and Sorooshian, S.: Estimation of physical variables from multichannel remotely sensed imagery using a neural network: Application to rainfall estimation, Water Resour. Res., 35, 1605-1618, 1999.

Huffman, G. J., Adler, R. F., Arkin, P., Chang, A., Ferraro, R., Gruber, A., Janowiak, J., McNab, A., Rudolf, B., and Schneider, U.: The Global Precipitation Climatology Project (GPCP) Combined Precipitation Dataset, B. Am. Meteorol. Soc., 78, 5-20, 1997.

Huffman, G. J., Bolvin, D. T., Nelkin, E. J., Wolff, D. B., Adler, R. F., Gu, G., Hong, Y., Bowman, K. P., and Stocker, E. F.: The TRMM Multisatellite Precipitation Analysis (TMPA): QuasiGlobal, Multiyear, Combined-Sensor Precipitation Estimates at Fine Scales, J. Hydrometeorol., 8, 38-55, doi:10.1175/jhm560.1, 2007.

Joyce, R. J., Janowiak, J. E., Arkin, P. A., and Xie, P. P.: CMORPH: A method that produces global precipitation estimates from passive microwave and infrared data at high spatial and temporal resolution, J. Hydrometeorol., 5, 487-503, 2004.

Legates, D. R. and Willmott, C. J.: Mean seasonal and spatial variability in gauge-corrected, global precipitation, Int. J. Climatol., 10, 111-127, 1990.

Pan, M., Li, H., and Wood, E.: Assessing the skill of satellite-based precipitation estimates in hydrologic applications, Water Resour. Res., 46, W09535, doi:10.1029/2009wr008290, 2010.

Romilly, T. G. and Gebremichael, M.: Evaluation of satellite rainfall estimates over Ethiopian river basins, Hydrol. Earth Syst. Sci., 15, 1505-1514, doi:10.5194/hess-15-1505-2011, 2011. 
Sapiano, M. R. P. and Arkin, P. A.: An Intercomparison and Validation of High-Resolution Satellite Precipitation Estimates with 3-Hourly Gauge Data, J. Hydrometeorol., 10, 149-166, doi:10.1175/2008jhm1052.1, 2009.

Schaefer, J. T.: The critical success index as an indicator of warning skill, Weather Forecast., 5, 570-575, doi:10.1175/15200434(1990)005<0570:tcsiaa > 2.0.co;2, 1990.

Shen, Y., Xiong, A., Wang, Y., and Xie, P.: Performance of highresolution satellite precipitation products over China, J. Geophys. Res., 115, D02114, doi:10.1029/2009jd012097, 2010.

Shi, X. Y., Wang, Y. Q., and Xu, X. D.: Effect of mesoscale topography over the Tibetan Plateau on summer precipitation in China: A regional model study, Geophys. Res. Lett., 35, L19707, doi:10.1029/2008g1034740, 2008.

Sohn, B. J., Han, H.-J., and Seo, E.-K.: Validation of Satellite-Based High-Resolution Rainfall Products over the Korean Peninsula Using Data from a Dense Rain Gauge Network, J. Appl. Meteorol. Clim., 49, 701-714, doi:10.1175/2009jamc2266.1, 2010.

Sorooshian, S., Hsu, K. L., Gao, X., Gupta, H. V., Imam, B., and Braithwaite, D.: Evaluation of PERSIANN system satellitebased estimates of tropical rainfall, B. Am. Meteorol. Soc., 81, 2035-2046, 2000.

Sorooshian, S., AghaKouchak, A., Arkin, P., Eylander, J., FoufoulaGeorgiou, E., Harmon, R., Hendrickx, J. M. H., Imam, B., Kuligowski, R., Skahill, B., and Skofronick-Jackson, G.: Advanced concepts on remote sensing of precipitation at multiple scales, B. Am. Meteorol. Soc., 92, 1353-1357, doi:10.1175/2011bams3158.1, 2011.
Sun, H. L. and Zheng, D.: The formation, evolution and development of Qinghai-Tibet Plateau, Guangdong Science and Technology Press, Guangdong, 350 pp., 1999.

Wang, J. Z., Yang, Y. Q., Xu, X. D., and Zhang, G. Z.: A monitoring study of the 1998 rainstorm along the Yangtze River of China by using TIPEX data, Adv. Atmos. Sci., 20, 425-436, 2003.

Xie, P., Chen, M., Yang, S., Yatagai, A., Hayasaka, T., Fukushima, Y., and Liu, C.: A Gauge-Based Analysis of Daily Precipitation over East Asia, J. Hydrometeorol., 8, 607-626, doi:10.1175/jhm583.1, 2007.

Yanai, M. H., Li, C. F., and Song, Z. S.: Seasonal heating of the tibetan plateau and its effects on the evolution of the asian summer monsoon, J. Meteorol. Soc. Jpn., 70, 319-351, 1992.

Yang, K., Ye, B. S., Zhou, D. G., Wu, B. Y., Foken, T., Qin, J., and Zhou, Z. Y.: Response of hydrological cycle to recent climate changes in the Tibetan Plateau, Climatic Change, 109, 517-534, 2011.

Yeh, D. Z. and Gao, Y. X.: The Meteorology of the Tibetan Plateau, Science Press, Beijing, 278 pp., 1979.

Yin, Z.-Y., Zhang, X., Liu, X., Colella, M., and Chen, X.: An Assessment of the Biases of Satellite Rainfall Estimates over the Tibetan Plateau and Correction Methods Based on Topographic Analysis, J. Hydrometeorol., 9, 301-326, doi:10.1175/2007jhm903.1, 2008. 